\title{
Narrativa de Aula de uma Professora sobre a Investigação Estatística
}

\section{E्己̌rêáa}

\author{
Regina Célia Grando' \\ Adair Mendes Nacarato' \\ Celi Espasandin Lopes"
}

'Universidade São Francisco (USF), Itatiba/SP - Brasil "Universidade Cruzeiro do Sul (UNICSUL), São Paulo/SP - Brasil

RESUMO - Narrativa de Aula de uma Professora sobre a Investigação Estatística. Este texto analisa a narrativa de aula de uma professora que ensina Matemática nos anos iniciais do Ensino Fundamental e que participa de um grupo que desenvolve uma pesquisa colaborativa, no âmbito do Projeto Observatório da Educação, com o objetivo de investigar os letramentos matemáticos escolares e as práticas de formação docente. Em sua narrativa, a professora descreve o processo de investigação estatística desenvolvido com uma turma de $1^{\circ}$ ano. A análise traz indícios de aprendizagens docente, relativos ao letramento estatístico das crianças - em particular, no que se refere ao desenvolvimento da linguagem gráfica-, e revela a apropriação de práticas de letramento pela professora.

Palavras-chave: Narrativa de Aula. Letramento Matemático. Letramento Estatístico. Aprendizagem Docente.

ABSTRACT - A Teacher's Lesson Narrative Regarding Statistics Investigation. In this paper we analyze the lesson narrative of a mathematics teacher for the Elementary School. She is a member of a group developing a collaborative research as part of the 'Educational Observation Project', aiming to investigate mathematical literacy and the teaching education practices of mathematics teachers. In her narrative, she describes the statistic investigation process developed with a $1^{\text {st }}$ grade group. There is evidence revealing the teacher's hints of learning related to the children's statistics literacy, mainly referring to the development of graphical language, as well as evidence of ownership of literacy practices by the teacher.

Keywords: Lesson Narrative. Mathematical Literacy. Statistical Literacy. Teacher Learning.

Educação \& Realidade, Porto Alegre, v. 39, n. 4, p. 985-1002, out./dez. 2014. 
Narrativa de Aula de uma Professora sobre a Investigação Estatística

\section{Introdução}

Este artigo decorre de uma investigação realizada no âmbito do Projeto Observatório da Educação (OBEDUC), financiado pela Capes e vinculado ao Programa de Pós-Graduação Stricto Sensu em Educação da Universidade São Francisco/USF. A pesquisa tem como objetivo geral investigar, por meio de um trabalho colaborativo com professoras da Educação Básica, as práticas de letramentos escolares, mais especificamente, o letramento matemático e as práticas de formação docente de professores que ensinam Matemática.

O grupo do projeto envolve duas professoras da USF, duas mestrandas, sete professoras da Escola Básica - todas atuando no ciclo de alfabetização ( $1^{\circ}$ ao $3^{\circ}$ ano) - e uma professora colaboradora. As professoras selecionam algumas de suas aulas, as registram em narrativas e as compartilham no grupo.

As narrativas são consideradas como práticas de formação, quando o professor, ao contar seus fazeres docentes, explicita a (re)elaboração de seus saberes e socializa seus processos criativos decorrentes dos desafios do trabalho docente. O compartilhamento, com os pares, das narrativas produzidas tem se revelado uma prática formativa: as professoras identificam-se com as práticas narradas, se autoavaliam como docentes que têm práticas similares (ou não) e apropriam-se de novas formas de trabalho pedagógico, produzindo sentidos para a sua atividade profissional.

A metodologia de pesquisa por nós adotada - entendida por Bertaux como "[...] fragmento(s) particular(es) de realidade social-histórica” (Bertaux, 2010, p. 16) - é de abordagem qualitativa e insere-se nas interfaces entre os estudos sobre o trabalho colaborativo e os estudos sobre as narrativas de vida ou narrativas de práticas em situação. Além disso, “[...] através das práticas, pode-se começar a compreender contextos sociais nos quais elas se inscrevem e que elas contribuem para reproduzir ou para transformar" (Bertaux, 2010, p. 17, grifo do autor).

O grupo se reúne quinzenalmente para estudos sobre letramentos, análises de documentos que chegam às escolas e de avaliações externas, elaboração de tarefas para a sala de aula e compartilhamento das práticas por meio de relatos orais e escritos.

As narrativas produzidas pelas professoras têm se constituído em documentação narrativa de práticas e cada uma delas possibilita múltiplos olhares, múltiplas interpretações.

Neste texto, trazemos uma dessas produções, na qual a professora I. M. narrou uma atividade com foco na investigação estatística, desenvolvida com crianças do $1^{\circ}$ ano do Ensino Fundamental de uma escola da rede pública municipal de Itatiba/SP. O relato da professora decorre de sua inserção em um grupo colaborativo em que a aprendizagem docente emerge de um processo propositivo, interativo e reflexivo que 
visa à apropriação e à mobilização de conhecimentos profissionais. Estes são redimensionados, quando as participantes fazem suas escolhas de estudos teóricos e metodológicos sobre os processos de letramento, analisam suas práticas, refletem sobre as práticas das colegas e ampliam seus repertórios de saberes.

Nosso objetivo, neste texto, é evidenciar os indícios de aprendizagem docente presentes em uma narrativa de aula da professora I. M., com foco no letramento estatístico. É importante destacar que, muito embora os conteúdos de estatística tenham sido inseridos apenas recentemente nos currículos de Matemática da Educação Básica, as investigações estatísticas dos alunos constituem práticas de letramento escolar e a produção de narrativas sobre essas investigações é uma das práticas de letramento docente.

O artigo está organizado em quatro seções, em que discutimos como a investigação estatística contribui para as práticas de letramento escolar; trazemos nossas concepções de narrativa, letramento e aprendizagem docentes; apresentamos a narrativa da professora I. M. e nossas análises sobre as aprendizagens da professora-narradora; e, finalmente, tecemos algumas reflexões sobre a investigação realizada.

\section{Investigação Estatística no Contexto das Práticas de Letramento}

Tradicionalmente, a Estatística tem sido ensinada como um conjunto de técnicas, e não como uma forma de pensar sobre o mundo. Atualmente, a educação estatística assume a perspectiva da análise exploratória de dados como eixo central (Scheaffer, 2000). Shaughnessy, Garfield e Greer (1996) afirmam que trabalhar na análise exploratória de dados é um estado de espírito, um ambiente em que se pode explorar dados, e não consiste apenas em um determinado conteúdo estatístico. Dessa forma, o trabalho com os estudantes deve permitir-lhes a percepção e a elaboração de modelos, regularidades, padrões e variações dentro dos dados.

Tais ideias direcionam ao debate e à importância do letramento estatístico - um dos possíveis letramentos escolares -, que tem sido denominado, por alguns pesquisadores, de literacia estatística, a qual pode ser vista como a capacidade para interpretar argumentos estatísticos, superando as competências computacionais e permitindo que, por meio de análises fundamentadas, se possam tomar decisões. Para Lopes, a literacia estatística requer “[...] que a pessoa seja capaz de reconhecer e classificar dados como quantitativos ou qualitativos, discretos ou contínuos, e saiba como o tipo de dado conduz a um tipo específico de tabela, gráfico, ou medida estatística" (Lopes, 2004, p. 187).

Gal (2002), ao discutir a literacia estatística de adultos, considera que esta seja uma habilidade-chave esperada de cidadãos em uma sociedade repleta de informações. Ele enumera cinco componentes bási-

Educação \& Realidade, Porto Alegre, v. 39, n. 4, p. 985-1002, out./dez. 2014

Disponível em: <http://www.ufrgs.br/edu_realidade> 
Narrativa de Aula de uma Professora sobre a Investigação Estatística

cos do conhecimento estatístico, que se fazem necessários para que um adulto seja letrado estatisticamente, ou seja, para que tenha habilidades para interpretar mensagens estatísticas. Primeiramente, ele afirma que é importante saber por que os dados são necessários e como eles podem ser produzidos. Depois, que é preciso ter familiaridade com termos e ideias relacionadas com as estatísticas descritivas básicas e relacionadas às representações em tabelas e gráficos. O autor assinala ainda a necessidade de entender as noções básicas da probabilidade e a forma como as conclusões ou inferências são obtidas.

Diante disso, vemos que o professor, durante seu processo de formação inicial ou continuada, precisa ter oportunidades para tornar-se letrado estatisticamente e ser capaz de promover a aprendizagem estatística de seus estudantes.

Quando planejamos o trabalho com letramento estatístico das crianças, visamos ao desenvolvimento de habilidades que lhes permitam aprender a interpretar, a avaliar e a interagir com informações estatísticas. Essa forma de letramento contribui para a ampliação da habilidade leitora e escritora em língua materna.

Essa perspectiva tem gerado a recomendação do trabalho com a investigação estatística desde a Educação Infantil (Lopes, 2003; Souza, 2007) e tem por objetivo que as crianças desenvolvam habilidades comunicativas, tanto orais quanto escritas, e também aprendam a raciocinar sobre o universo infantil.

O processo de desenvolvimento de uma investigação estatística contribui para que os estudantes aprendam a mapear temáticas de seu interesse e a conhecer sua realidade, à medida que problematizam situações, levantam conjecturas, formulam hipóteses, estabelecem relações, a fim de tirar conclusões e/ou tomar decisões. Nesse sentido, eles precisam ter a oportunidade de adquirir a compreensão da lógica das pesquisas estatísticas, desenvolvendo ideias sobre a natureza e os processos de uma pesquisa. Parte-se da formulação do problema e da pergunta subjacente ao tema que se quer investigar, planeja-se a coleta das informações, depois se as organiza, explorando e analisando os dados e, posteriormente, finaliza-se o processo, interpretando, discutindo e tomando decisões sobre a temática investigada.

Vivenciar essa atividade possibilita o desenvolvimento do raciocínio estatístico, que se refere ao modo como as pessoas raciocinam com as ideias estatísticas.

Raciocinar estatisticamente significa entender e ser capaz de explicar os processos estatísticos, e ser plenamente capaz de interpretar os resultados estatísticos, remetendo ao pensamento estatístico que requer uma compreensão do por que e como são conduzidas investigações estatísticas. Isto inclui reconhecer e compreender todo o processo investigativo desde a pergunta elaborada, passando pela 
escolha dos instrumentos para a construção dos dados até o processo de interpretação e análise (Lopes, 2012, p. 168 , grifos da autora).

No início da escolarização, a criança está construindo o conceito de número e em fase de compreender a constituição do sistema de numeração decimal. Trabalhar com análise exploratória de dados, nessa etapa, contribui para o processo de entender o mundo expresso em números, pois, na Estatística, os dados são vistos como números num contexto, e este motiva os procedimentos e é a base para a interpretação dos resultados.

Nesse sentido, é muito importante que se considere a cultura infantil como contexto de investigação estatística, uma vez que ela se distingue de uma exploração matemática mais precisa e com uma natureza mais finita. O fundamental, nos problemas estatísticos, é que, pela sua natureza, eles não têm uma solução única e não podem ser avaliados como totalmente errados nem certos, devendo ser analisados em termos da qualidade do raciocínio e da adequação dos métodos utilizados à natureza dos dados existentes (Gal; Garfield, 1997).

Esse movimento do fazer estatístico na infância também permite que as crianças expressem representações pictóricas e gráficas atreladas ao significado que atribuem à informação a ser comunicada. Dessa forma, podem-se evitar possíveis dificuldades dos alunos, decorrentes do tratamento qualitativo paralelo ao tratamento quantitativo necessário na linguagem gráfica.

De acordo com Curcio (1987 apud Lopes, 2004), o conhecimento de uma pessoa sobre um determinado tipo de gráfico depende do fato de ela ter sido exposta a uma experiência anterior significativa com uma dessas formas de representação. Para ele, três fatores são fundamentais para a compreensão do gráfico: o reconhecimento do tipo de gráfico, as relações matemáticas existentes entre os números e suas respectivas ideias, e as operações matemáticas envolvidas.

O domínio da linguagem gráfica implica a capacidade de leitura dos dados presentes em um gráfico, permitindo que o leitor consiga interpretá-los e generalizar as informações nele presentes. Dessa forma, existe uma evolução na compreensão das pessoas sobre as diferentes formas de representação, o que supera a dicotomia entre construção e interpretação.

Para Curcio (1989 apud Lopes, 2004), a compreensão dos gráficos perpassa a leitura dos dados, a leitura entre os dados e a leitura além dos dados. Inicialmente, a pessoa limita-se a ler literalmente o gráfico, retirando os fatos explícitos, lendo a informação descrita nos eixos ou na legenda, sem realizar qualquer interpretação.

Ao ler entre os dados, a pessoa realiza alguma interpretação deles e da forma como estão integrados no gráfico e mostra-se capaz de comparar quantidades, ao mesmo tempo em que recorre a outros conceitos

Educação \& Realidade, Porto Alegre, v. 39, n. 4, p. 985-1002, out./dez. 2014 989 Disponível em: <http://www.ufrgs.br/edu_realidade> 
Narrativa de Aula de uma Professora sobre a Investigação Estatística

e capacidades, que lhe permitem identificar as relações matemáticas ali presentes. Nesse momento, ela começa a realizar inferências de natureza simples.

Já, na leitura para além dos dados, a pessoa é capaz de inferir ou predizer um determinado resultado ou acontecimento em função de vários conhecimentos e não apenas baseando-se em alguma informação apresentada no gráfico. Ao atingir esse patamar, ela adquire condição de responder a perguntas implícitas, tendo como base as extrapolações, as previsões ou as inferências realizadas a partir de uma interpretação. Nessa perspectiva, entendemos que a pessoa amplia sua leitura de mundo, sendo capaz de compreender com criticidade informações estatísticas que circulam na nossa sociedade letrada.

Para que os alunos possam adquirir todas essas habilidades na linguagem estatística, é preciso que o trabalho se inicie desde a infância, de forma vinculada à resolução de situações-problema.

Lopes (2003) considera que o trabalho com Estatística deve desenvolver-se por meio da resolução de situações-problema, nas quais os professores planejem o processo de estudo de uma problemática qualquer. Eles precisam ser capazes de, junto com as crianças, formular uma questão ou determinar um tema de investigação, definir os instrumentos de coleta de dados, organizar e escolher a representação mais adequada para comunicá-los. Posteriormente, realizarão a análise dos dados já tratados, interpretarão as descobertas, discutindo as possíveis conclusões e implicações.

Dessa forma, consideramos que aquilo a ser aprendido tem que fazer sentido para o sujeito, no contexto de suas aprendizagens e de seus conhecimentos, e, ao mesmo tempo, mobilizar interesses, motivos e expectativas (Souza, 2013), além de possibilitar novas formas de leitura e interpretação de informações.

O grupo do Obeduc tem se debruçado sobre uma ampliação do construto teórico letramentos. Estamo-nos aproximando das ideias de Bunzen sobre o letramento escolar: para ele, o letramento escolar pode ser "[...] compreendido como um conjunto de práticas socioculturais, histórica e socialmente variáveis, que possui uma forte relação com os processos de aprendizagem formal da leitura e da escrita, transmissão de conhecimentos e (re)apropriação de discursos" (Bunzen, 2010, p. 110). Dentre os múltiplos letramentos escolares, temos investido nas práticas de letramento matemático, estatístico e docente.

A discussão sobre práticas de letramento docente ainda é recente na literatura. Elas podem ser entendidas como as formas como os docentes são capazes de ler e interpretar os diferentes textos que chegam à escola (legislações, normativas, documentos curriculares, livro didático, materiais didáticos diversos, provas externas, dentre outros), interligando-os com contextos mais amplos das políticas públicas, bem como registrando e sistematizando suas práticas, por meio de narrativas de 
relatos de experiências e de artigos para apresentação em eventos ou publicação em livros e periódicos - prática que tem sido adotada no grupo Obeduc. As produções das professoras vêm carregadas de leituras e interpretações possíveis da complexidade da realidade escolar. As práticas de letramento docente estão diretamente interligadas às práticas de letramento que o professor desenvolve em sua sala de aula e no coletivo da escola.

Dentre as múltiplas formas de letramento escolar, estamos aqui focalizando a produção de narrativas docentes, visto que elas dão visibilidade tanto das práticas de letramento em sala de aula, quanto do próprio letramento docente, além de se constituírem em práticas de formação.

\title{
A Produção de Narrativas de Aula Potencializando as Aprendizagens Docentes
}

A pesquisa sobre a formação do professor tem evidenciado as contribuições do grupo colaborativo, pois “[...] o trabalho colaborativo e reflexivo é organizado por meio de ações formativas que auxiliam no processo de coprodução de conhecimentos" (Ibiapina, 2008, p. 47).

O professor, ao inserir-se em espaços formativos que priorizam o processo de reflexividade, analisa sua prática por meio de estudos teóricos que lhe permitem redimensionar a prática e criar tarefas significativas para os contextos com os quais trabalham. Nesses espaços, os estudos tomam como ponto de partida as práticas dos professores. Isso nos leva a concordar com Jaworski (2008), ao considerar que é mais relevante que as teorias e as sugestões venham de dentro da cultura escolar.

Tal abordagem tem sido contemplada no projeto de pesquisa que assume a concepção de formação contínua, na perspectiva do desenvolvimento profissional, entendido como:

\begin{abstract}
[...] um processo pessoal, permanente, contínuo e inconcluso que envolve múltiplas etapas e instâncias formativas. Além do crescimento pessoal ao longo da vida, compreende também a formação profissional (teórico-prática) da formação inicial - voltada para a docência e que envolve aspectos conceituais, didático-pedagógicos e curriculares - e o desenvolvimento e a atualização da atividade profissional em processos de formação continuada após a conclusão da licenciatura. A formação contínua, portanto, é um fenômeno que ocorre ao longo de toda a vida e que acontece de modo integrado às práticas sociais e às cotidianas escolares de cada um, ganhando intensidade e relevância em algumas delas (Passos et al., 2006, p. 195).
\end{abstract}

Assumimos que, no processo de desenvolvimento profissional, o professor aprende, produz sentidos e significados para o seu fazer pedagógico, quando se insere em grupos colaborativos; sistematiza suas 
Narrativa de Aula de uma Professora sobre a Investigação Estatística

práticas, registrando-as; compartilha-as e reflete sobre elas e as de seus pares; e assume-se como protagonista de sua prática. Aprender é produzir significados, e a aprendizagem docente não está dissociada da atividade profissional.

Acreditamos que, no grupo Obeduc, ao realizarmos um trabalho em parceria com um grupo de professoras dos anos iniciais do Ensino Fundamental, provocamos movimentos de aprendizagens docente, marcados pelo questionamento, pela problematização, pela investigação e pela reflexão sobre as práticas escolares conjuntamente.

Consideramos o professor um produtor de conhecimentos e a investigação como centro do fazer docente. Reconhecemos neste profissional um protagonista da própria prática e do desenvolvimento curricular, que pode tornar-se consumidor crítico das teorias produzidas pelas pesquisas acadêmicas e reavaliar seu cotidiano escolar.

Estamos, pois, defendendo as possibilidades de formação docente em comunidades investigativas. No entanto, há também que considerar que a constituição dessas comunidades demanda tempo e dedicação dos envolvidos. Dessa maneira, questionamos o sentido de falar em professor investigador, com as condições de trabalho docente dos professores brasileiros: baixa remuneração; salas numerosas; intensificação do trabalho desses profissionais; não vinculação a uma única escola; tensões diante das prescrições que chegam até a escola; e controle do trabalho via avaliações externas. Nesse aspecto, o Programa Observatório de Educação, ao oferecer bolsas aos professores, possibilita colocá-los na condição de investigadores e viabilizar sua proposta. Se a constituição de parcerias entre acadêmicos e professores é fundamental para tais comunidades (Jaworski, 2008), os participantes de uma comunidade investigativa devem unir-se em ações dirigidas por objetivos. Nosso propósito no grupo Obeduc tem sido realizar pesquisas com o professor, de forma colaborativa.

Em síntese, é no movimento de análise compartilhada de situações cotidianas, análise de avaliações externas, reflexões teóricas, produções de registros reflexivos e narrativas de aulas, escrita acadêmica de textos e constituição de um corpus teórico sobre letramentos - dentre eles, o letramento matemático escolar-, que o professor se desenvolve profissionalmente. Nesse movimento, todos aprendem colaborativamente. Para nós, a aprendizagem docente implica em transformações da prática e do cotidiano escolar. Também nós, como pesquisadoras, aprendemos, no movimento de produzir os estranhamentos no cotidiano escolar, ouvindo os professores sobre suas práticas e conhecendo um pouco mais sobre essa realidade da escola pública atual, uma vez que já fomos professoras da Educação Básica há certo tempo. Fazer parceria com as professoras possibilita-nos essa aproximação e a possibilidade de teorizações conjuntas com elas.

A narrativa de I. M., apresentada a seguir, corrobora uma possibilidade de aprendizagem apontada por Placo e Souza (2006, p. 76), pois, 
quando o professor pode expressar-se para o outro, sabendo-se escutado e não julgado, passa a ver-se e escutar-se e, muitas vezes, engendra mudanças a partir de sua própria reflexão. Dentre as diferentes perspectivas de dar voz ao professor, temos adotado a escrita de narrativas de aulas.

Dessa forma, há uma aprendizagem compartilhada por quem escreve a narrativa e por quem a lê, pois:

[...] a narrativa contribui tanto para o leitor, quanto para o produtor. No ato de escrita da narrativa, a professora não apenas precisa se lembrar dos fatos passados, como também construir um cenário, uma trama na qual a história se passa, suas personagens e suas ações (Nacarato; Passeggi, 2011, p. 3).

O narrador também precisa levar em consideração quem será o leitor dessa história. Todo texto pressupõe um leitor. E mais: no momento da escrita, há todo um processo de reflexão sobre a experiência a ser narrada. Esse é o momento em que se atribuem sentidos e significados ao que se faz. Por isso, a narrativa é a forma primária pela qual a experiência humana ganha significado. Ela possibilita organizar a experiência. Portanto, as experiências provocam mudanças identitárias, o que é possível a partir de situações de reflexão e problematização das práticas, quando estas são narradas e discutidas num grupo, com os pares. A leitura de narrativas de práticas de colegas possibilita ao professor refletir sobre sua própria prática, identificar-se com a aula narrada, com o seu contexto, com as falas dos alunos e com a cultura da escola. Submeter sua criação à crítica e buscar novas estratégias para (re)elaborar o seu fazer docente são aspectos que potencializam o aprendizado (Oliveira, 2013) do professor narrador.

Aprender envolve atribuir significações e cria relações únicas com o saber. Mobiliza experiências vividas pelo sujeito, em sua interação com outros significados e em sua inserção no mundo. É um processo permeado por afetos, desejos, expectativas, vontades, os quais interferem na aprendizagem e também são aprendidos (Placo; Souza, 2006).

Na narrativa de I. M., analisada a seguir, podemos perceber o movimento da professora, ao confrontar-se com o desafio de desenvolver a investigação estatística com as crianças.

\section{A Narrativa de I. M.: quando as crianças estão envolvidas em uma situação de pesquisa e investigação, ampliam as suas experiências de apropriação do conhecimento matemático}

A narrativa de aula ou narrativa de práticas constitui um gênero de discurso, na concepção de Bakhtin (2003). Produzi-la tem uma função - compartilhar com os pares as práticas de sala de aula - e, portanto, exige "[...] determinadas condições de comunicação discursiva”

Educação \& Realidade, Porto Alegre, v. 39, n. 4, p. 985-1002, out./dez. 2014 
Narrativa de Aula de uma Professora sobre a Investigação Estatística

(Bakhtin, 2003, p. 266). Em sua narrativa, é usual que a professora-narradora fale sobre o contexto de sua prática. Como gênero discursivo e textual, a narrativa de aula traz o estilo da professora-narradora, mas tem um conteúdo composicional: há um momento de auto identificação (quem é, onde atua, com qual turma), de contextualização de seu trabalho (como são os alunos, quando o trabalho foi realizado, o conteúdo trabalhado, os materiais utilizados); existem as personagens (os alunos e a professora) e a trama (como foi o desenvolvimento da ação que está sendo narrada). Geralmente, termina com uma reflexão da professora-narradora sobre a prática narrada.

I. M. inicia sua narrativa, informando ao leitor que sua turma de $1^{\circ}$ ano é composta de 24 alunos e que faz parte da sua rotina escolar a marcação do tempo por meio de calendário, utilizando a contagem em situações diversas. A partir disso, elabora uma tarefa que tem por objetivos: a comunicação de quantidades, utilizando a linguagem oral, notação numérica e registros convencionais ou não; a comparação de escritas numéricas; o uso de oralidade para comunicar ideias; a leitura de imagem e símbolos diversos (tabelas e gráficos); e a circulação de ideias, dúvidas e observações.

O desenvolvimento da tarefa inicia-se pela problematização que I.M. apresenta para a turma: O que é aniversário? Essa era uma tarefa que constava do livro didático de uso na turma. No entanto, o livro propõe apenas o preenchimento da tabela (Figura 1). A professora, inicialmente, fez o que o livro sugere, levantando a data de nascimento das crianças e preenchendo a tabela com os alunos.

Figura 1 - Tabela de Aniversários

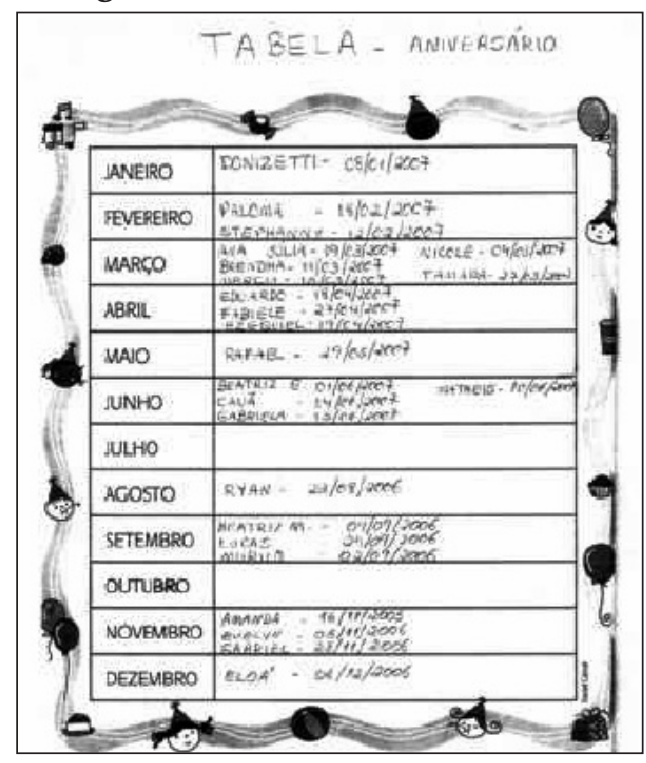

Fonte: Narrativa de I. M. (2013). 
Podemos observar que a professora poderia ter escrito apenas o nome de cada criança, no mês correspondente ao aniversário, o que simplificaria a leitura dos dados, já que a intenção era mapear a quantidade de crianças aniversariantes em cada mês, como mostra o gráfico apresentado na Figura 2.

\section{Figura 2 - Gráfico dos Aniversários}

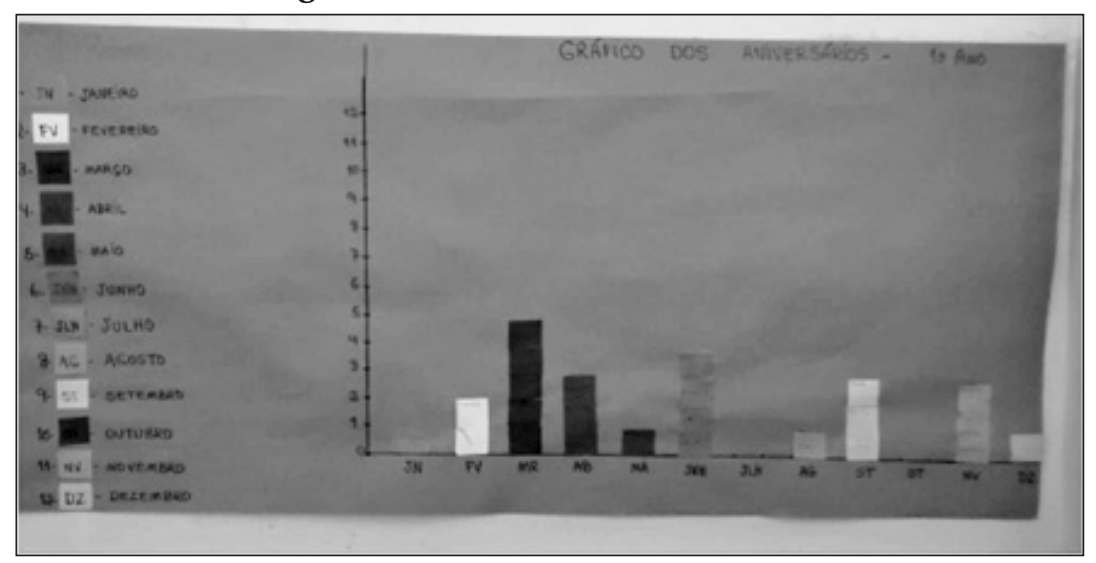

Fonte: Narrativa de I. M. (2013).

Isso revela inexperiência da professora no trabalho com a investigação estatística, o que é natural, tendo em vista a pouca atenção que vem sendo dada ao estudo da temática, nos processos de formação docente inicial e continuada. Na formação inicial, muitas vezes, insiste-se na disciplina de Estatística aplicada à Educação e poucas vezes há discussão sobre a Educação Estatística nessa disciplina.

A professora I. M., ao inserir-se em um grupo de pesquisa colaborativo com foco no letramento, assumiu sua intenção de transformar suas práticas e expressa sua disponibilidade para socializá-las por meio da produção de narrativas. Essa atitude revela uma busca da superação das lacunas deixadas pela formação inicial, pois, ao socializar sua narrativa no grupo, a professora sabe que receberá contribuições das colegas para ampliar suas ações e para refletir sobre a condução da tarefa e sobre as formas de pensamento das crianças.

No desenvolvimento das atividades com os alunos, ela evidencia sua atenção a detalhes importantes para a compreensão das crianças. Por exemplo, ao registrar a data de nascimento de cada um, ela possibilita que acessem outro tipo de informação: os aniversários de seus colegas.

A professora I. M. revelou também um cuidado especial com o desenvolvimento da linguagem gráfica, o que pode ser observado no diálogo, transcrito a seguir, que ela estabeleceu com as crianças:

Lucas: Tem mês que ficou igual

Questionei por quê.

Educação \& Realidade, Porto Alegre, v. 39, n. 4, p. 985-1002, out./dez. 2014. 
Narrativa de Aula de uma Professora sobre a Investigação Estatística

Ezequiel: Porque tem 3 (abril, setembro e novembro)

Outros meses com a mesma quantidade foram mencionados:

Eduardo: Tem quatro com apenas 1 (janeiro, maio, agosto e dezembro). Como ele ainda não consegue nomear os meses levantou-se e foi mostrar. Aluna Eloá falava os meses conforme eram mostrados pelo colega.

Brendha fez um comentário sobre os meses que não tinham aniversariantes, julho e outubro.

Perguntei qual número representaria aquela situação. Vários alunos responderam que era o 0 (zero).

Fiz nova proposta à sala:

Quantos quadradinhos foram colados no gráfico?

Levantaram para contar. Nenhum aluno observou a contagem do dia que constava a presença de $100 \%$ da sala, ou seja, 24 alunos (I. M., 2013, p. 3).

Além dessa preocupação com a leitura dos dados, I. M. ampliou as possibilidades de desenvolvimento da linguagem gráfica, buscando a leitura entre os dados (Curcio, 1989 apud Lopes, 2004). Para isso, ela organizou, em sala de aula, com as crianças, uma tabela correspondente ao levantamento realizado (Figura 3). Em seguida, levou as crianças para a quadra de esportes da escola, escreveu o nome dos meses no chão, um ao lado do outro, e solicitou que elas se posicionassem na coluna correspondente ao mês de seu aniversário. Essa ação revelou a preocupação da professora em possibilitar às crianças a percepção sobre a correspondência existente entre o dado coletado e a representação dele na tabela ou no gráfico.

Figura 3 - Tabela com Número de Aniversariantes em cada Mês

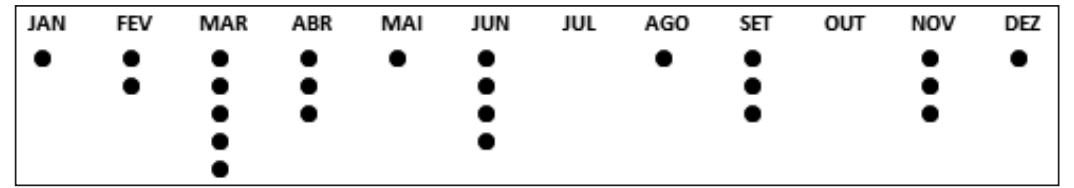

Fonte: Narrativa de I. M. (2013).

Essa etapa delineada por I.M. tinha uma intenção muito pertinente em relação à proposta que viria em seguida, quando ela propôs que as crianças se posicionassem em círculo na quadra (Figura 4). Ela relata:

Tracei um círculo imaginário e comecei chamando o aniversariante de janeiro, saindo com o barbante do centro do círculo até seus pés, pedi que colocasse os dois pés sobre o barbante esticado e voltei até o centro, formando a primeira fatia da pizza. Assim prosseguimos até o mês de dezembro.

Contornei a marcação do barbante com o giz e retiramos todo o barbante para que ficassem à vontade.

Escrevi o nome do mês em cada fatia.

Observação: Nesse dia o aluno Ezequiel faltou e Lucas sugeriu que desenhássemos o colega no seu lugar (I. M., 2013, p. 5). 
Figura 4 - Gráfico de Setores

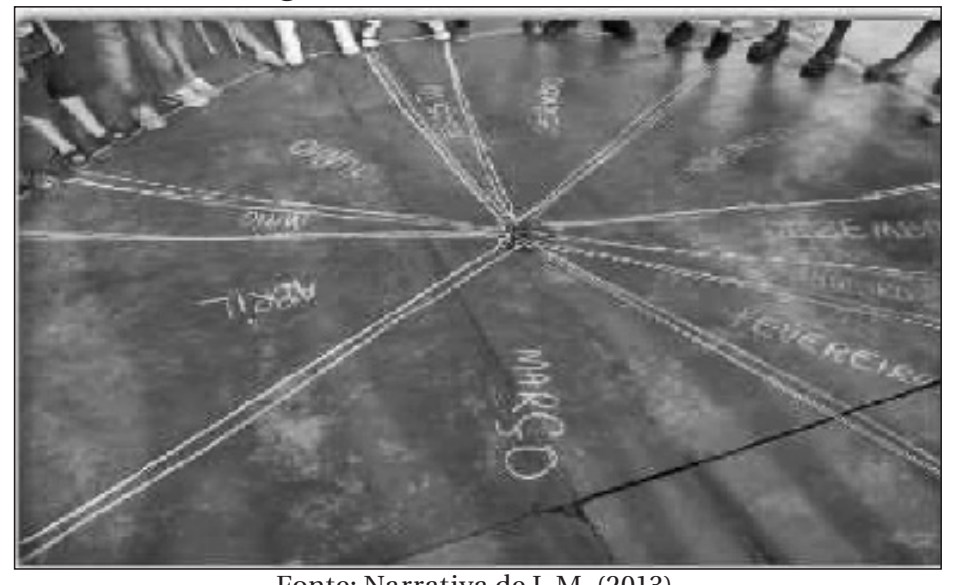

Fonte: Narrativa de I. M. (2013).

A professora criou uma forma de compreensão gráfica adequada à faixa etária, ao pedir que cada aluno ocupasse o espaço correspondente ao mês em que nasceu. Dessa forma, em cada setor do círculo, tinha-se $o$ aluno que correspondia ao dado representado na tabela. Isso permitiu que as crianças compreendessem, a partir de seu posicionamento no círculo, o que representa o gráfico construído, posteriormente, no Excel (Figura 5).

Figura 5 - Gráfico dos Aniversários

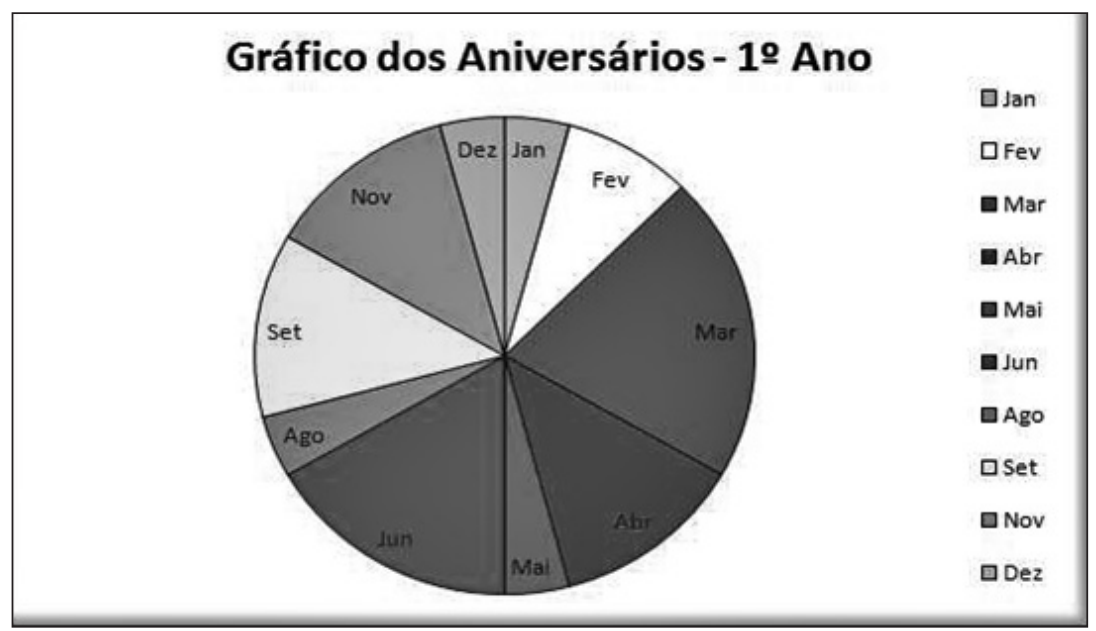

Fonte: Narrativa de I. M. (2013).

A narrativa de I. M. revela, como indicado por Gal (2002) e Lopes (2004), seu letramento estatístico, ao ser capaz de reconhecer e classificar dados e apresentar familiaridade com as representações em tabelas 
Narrativa de Aula de uma Professora sobre a Investigação Estatística

e gráficos. Esses conhecimentos lhe permitiram elaborar e desenvolver propostas adequadas à aprendizagem matemática e estatística das crianças, ao relatar:

Enquanto o gráfico era construído, surgiram muitos comentários. Citarei apenas alguns:

Stephanny: Olha o tamanho do pedaço. É grande, se tiver bastante criança. Veja aqui (mês de março). Neste dia, tem cinco aniversários.

Eloá: Não éo dia! Nós não fazemos aniversário no mesmo dia! O mês é igual! Brendha: Março ficou com o maior pedaço.

Eduardo: Formou um pedaço com pouca e bastante pizza (grande e pequeno).

Gabriel: O primeiro pedaço dessa pizza foi do Donizetti, porque ele fez aniversário primeiro que todos e da Eloa é o último.

Stephanny completou o pensamento do colega: O Donizetti nasceu primeiro, e a Eloá nasceu por último!

Aqui surgiu uma nova questão a se trabalhar: a linha do tempo, pois Eloá nasceu um ano antes do Donizetti, portanto é mais velha que ele.

Comentei, naquele momento, que o que estava sendo mostrado com todas aquelas atividades era o número de aniversariantes de cada mês. Para pensarmos sobre o dia de aniversário, teríamos de fazer outra coleta de dados. Voltamos à sala e solicitei que fizessem um registro da atividade, através de desenho, observando se alguém consultaria o gráfico para coletar dados precisos.

Os alunos Gabriela, Matheus e Nicole levantaram-se várias vezes, contaram apenas o número de aniversariantes do seu mês de aniversário, mas isso não apareceu no registro. Já outros alunos fizeram registros muito interessantes, preocupando-se com os detalhes de informação (I. M., 2013, p. 5-6).

Essas reflexões das crianças indicam a leitura entre os dados (Curcio 1989 apud Lopes, 2004), objetivo da professora.

I. M. avaliou que seus alunos entraram em contato com um conteúdo matemático muito rico e significativo. Sua reflexão sobre essa prática superou suas expectativas e lhe permitiu analisar que ela conseguiu abordar a matemática, integrando os vários blocos de conteúdos.

Enquanto professora, minhas expectativas foram além, consegui manter um equilíbrio entre números e operações, espaço e forma, medida e tratamento de informação, houve regularidade no passo a passo envolvendo a resolução dos problemas que foram ocorrendo, pois acredito que tais propostas permitem ao aluno ampliar experiências de apropriação da matemática (I. M., 2013, p. 9).

Identificam-se, nesse excerto da narrativa de I. M., reflexões sobre suas aprendizagens. Com certeza, ao sistematizar sua prática e registrá-la numa narrativa para ser compartilhada com o grupo, ela tomou consciência sobre o envolvimento dos alunos em atividades que lhes eram significativas. $\mathrm{O}$ ato de narrar mobiliza reflexões sobre a prática de sala de aula e a partir dela. 
Destacamos quão criativa a professora foi, quando ampliou uma tarefa do livro que consistia apenas no preenchimento de uma tabela. Ao realizar todo esse movimento de ideias estatísticas e matemáticas com seus alunos, ela evidenciou quanto o professor pode criar a partir de uma proposta de um material didático. Isso revela como ela tem se apropriado das discussões, das quais tem participado, sobre os modos de ensinar matemática aos seus alunos. Esta se constitui uma prática de letramento do professor, que reconhece no material didático um possível apoio para um letramento estatístico dos alunos.

\section{Algumas Evidências Extraídas dessa Narrativa}

A narrativa de aula da professora I. M. indica que ousar outras práticas nas aulas para ensinar Matemática é incentivado pela participação em um grupo colaborativo no qual os participantes discutem referenciais teóricos e metodológicos e práticas de sala de aula que lhes possibilitam a segurança para novas ações docentes.

A narrativa de aula de I. M. evidencia possibilidades de trabalho com a linguagem gráfica, o que contribui para o letramento estatístico das crianças. Isso permite indicar rupturas com algumas concepções padronizadas de aulas de Matemática, construídas pelos professores ao longo de sua trajetória escolar/acadêmica, e também a ruptura com crenças de que crianças pequenas e não leitoras não têm condições de pensar matematicamente (Souza, 2007) e de trabalhar com análise de gráficos.

A mediação gerada pelo grupo colaborativo possibilitou que a professora I. M. expressasse seu caminhar e, por meio do coinvestimento, produzisse conhecimentos estatísticos e protagonizasse o redirecionamento curricular de forma autônoma, inserindo seus alunos em práticas de letramento.

Cabe destacar que a professora teve o cuidado de trabalhar com um contexto que faz parte do cotidiano das crianças, os aniversários, o que evidencia seu conhecimento sobre a necessidade de elas atribuírem significados ao estudo que realizam, bem como sua compreensão sobre a importância, para a vida de seus alunos, de uma aproximação do letramento estatístico.

A prática da professora revela que a inserção em um grupo colaborativo tem lhe permitido ampliar seu conhecimento teórico-metodológico, no que se refere às práticas de letramento escolar: matemático, estatístico e digital - quando ela leva os alunos à aula de informática e faz parceria com o monitor, para a construção do gráfico no Excel. Isso ocorre porque ela se assume protagonista em seu processo de desenvolvimento profissional (Passos et al., 2006). Ao sentir-se pertencente a um grupo de trabalho colaborativo, leva o sentido dessa colaboração também para o espaço escolar e faz parcerias com as crianças e com

Educação \& Realidade, Porto Alegre, v. 39, n. 4, p. 985-1002, out./dez. 2014

Disponível em: <http://www.ufrgs.br/edu_realidade> 
Narrativa de Aula de uma Professora sobre a Investigação Estatística

os colegas, acreditando nas possibilidades de aprendizagens por meio dessas parcerias.

No movimento entre narrar e refletir, a professora produz sentidos para as experiências vividas. Como analisa Delory-Momberger (2008, p. 90), numa relação dialógica entre teoria e prática, ela busca validar os saberes produzidos em sala de aula:

O questionamento ao qual convida o reconhecimento das aquisições da experiência não incide tanto sobre o fato da produção do saber na experiência, mas na compreensão das condições de produção desse saber e dos processos que permitem sua conscientização e sua formalização para fins de validação social (Delory-Momberger, 2008 p. 90).

Concordamos com a autora. Os saberes da experiência não são facilmente apreendidos. Como eles estão "[...] ligados à ação, trata-se de saberes compósitos, heterogêneos, parcelados, descontínuos, que não podem coincidir com os recortes formais dos saberes disciplinares" (Delory-Momberger, 2008, p. 90). Assim, a narrativa de práticas de sala de aula pode ser um gênero de discurso que possibilita, por parte da professora-narradora, a tomada de consciência de esses saberes e das relações que estabelece com eles.

Isso se evidencia na narrativa de I. M. ao explicitar a forma como conduziu suas aulas, o texto traz evidências de aprendizagens decorrentes da própria participação no grupo: 1) ampliar uma proposta presente no livro didático, articulando diferentes modos de coletar, organizar e comunicar dados em práticas de letramentos (Gal, 2002; Lopes, 2004);2) produzir uma narrativa de aula que se constitui em gênero discursivo (Bakhtin, 2003), em práticas de (auto)formação (Nacarato; Passeggi, 2011) e em letramento docente; 3) compreender que as práticas de letramento escolar são integradoras de várias áreas do conhecimento.

No que se refere ao ato de narrar das professoras do grupo, temos constatado que as narrativas, fragmentos de suas experiências cotidianas, podem se constituir em formas de registrar o vivido, possibilitando a construção da memória, como possibilidade de ressignificar, posteriormente, essas memórias cheias de significados. Podemos dizer que essas narrativas, fragmentos da história vivida, se entrelaçadas, possibilitam a tecedura de uma trajetória profissional, a história de práticas pedagógicas. Constituem fragmentos de uma história de vida e ganham valor quando registradas.

Como gênero discursivo, a narrativa tem um propósito: comunicar uma experiência. E, certamente, a professora-narradora espera que seu texto seja lido e comentado e a prática relatada seja (re)validada.

Como prática de formação, temos adotado a produção de narrativas de aulas, pelo fato de que elas, além de possibilitarem o registro de experiências, constituem-se em literatura que pode ser trabalhada com futuros professores ou professores em exercício. Constitui, ainda, uma

1000 Educação \& Realidade, Porto Alegre, v. 39, n. 4, p. 985-1002, out./dez. 2014. Disponível em: <http://www.ufrgs.br/edu_realidade> 
documentação sobre culturas escolares - documentação narrativa de professoras -, pois as narrativas possibilitam que se registrem práticas e modos pedagógicos de ensinar matemática num dado tempo e num determinado espaço. Elas compõem também práticas de letramentos docentes.

Recebido em 25 de março de 2014 Aprovado em 13 de maio de 2014

\section{Referências}

BAKHTIN, Mikail. Estética da Criação Verbal. Tradução de Paulo Bezerra. 4. Ed. São Paulo: Martins Fontes, 2003.

BERTAUX, Daniel. Narrativas de Vida: a pesquisa e seus métodos. Natal: EDUFRN; São Paulo: Paulus, 2010.

BUNZEN, Clécio. Os Significados do Letramento Escolar como uma Prática Sociocultural. In: VÓVIO, Cláudia L.; SITO, Luanda; GRANDE, Paula B. (Org.). Letramentos: rupturas, deslocamentos e repercussões de pesquisa em linguística aplicada. Campinas: Mercado de Letras, 2010. P. 99-120.

DELORY-MOMBERGER, Christine. Biografia e Educação: figuras do indivíduo-projeto. Trad. Maria da Conceição Passeggi, João Gomes da S. Neto e Luís Passeggi. Natal: EDUFRN; São Paulo: Paulus, 2008.

GAL, Iddo. Adults' Statistical Literacy: meanings, components, responsibilities. International Statistical Review - International Statistical Institute, Voorburg/ Holanda, v. 70, n. 1, p. 1-51, 2002.

GAL, Iddo; GARFIELD, Joan B. Curricular Goals and Assessement Challenges in Statistics and Education. In: GAL, Iddo; GARFIELD, Joan B. (Org.). The Assessment Challenges in Statistical Educational. Voorburg/Holanda: International Statistical Institute, 1997. P. 37-51.

IBIAPINA, Ivana M. L. M. Pesquisa Colaborativa: investigação, formação e produção de conhecimentos. Brasília: Liber Livro, 2008.

JAWORSKI, Barbara. Building and Sustaining Inquiry Communities in Mathematics Teaching Development. In: KRAINER, Konrad; WOOD, Terry (Org.). Participants in Mathematics Teacher Education: individuals, teams, communities and networks. The International Handbook on Mathematics Teacher Education. Rotterdam, The Nerthelands: Sense publisher, v. 3, 2008. P. 309-330.

LOPES, Celi. E. O Conhecimento Profissional dos Professores e suas Relações com Estatística e Probabilidade na Educação Infantil. 2003, 290f. Tese (Doutorado em Educação) - Programa de Pós-Graduação em Educação, Universidade Estadual de Campinas, Campinas, Brasil, 2003.

LOPES, Celi. E. Literacia Estatística e INAF 2002. In: FONSECA, Maria da Conceição. Letramento no Brasil: habilidades matemáticas. São Paulo: Global, 2004. P. 187-197.

LOPES, Celi. E. A Educação Estocástica na infância. Revista Eletrônica de Educação, v. 6, n. 1, maio 2012. Disponível em: <http://www.reveduc.ufscar.br/index.php/reveduc/article/viewFile/396/179>. Acesso em: 13 out. 2013.

NACARATO, Adair M.; PASSEGGI, Maria Conceição. Narrativas da Experiência Docente em Matemática de Professoras-Alunas em um Curso de Pedagogia. In: SIMPÓSIO INTERNACIONAL DE ESTUDOS DE GÊNEROS TEXTUAIS - SIGET, 6., 16 a 19 de ago. de 2011, Natal. Anais Eletrônicos... Natal, 2011. P. 1-14.

Educação \& Realidade, Porto Alegre, v. 39, n. 4, p. 985-1002, out./dez. 2014.1001 Disponível em: <http://www.ufrgs.br/edu_realidade> 
Narrativa de Aula de uma Professora sobre a Investigação Estatística

OLIVEIRA, Débora. As Aprendizagens dos Professores que Ensinam Matemática para Crianças ao se Inserirem em um Espaço Formativo sobre Estocástica. 2013. 139 f. Tese (Doutorado em Ensino de Ciências e Matemática) - Programa de Pós-Graduação em Ensino de Ciências e Matemática, Universidade Cruzeiro do Sul, São Paulo, 2013.

PASSOS, Cármen L. B. et al. Desenvolvimento Profissional do Professor que Ensina Matemática: uma meta-análise de estudos brasileiros. Quadrante, Portugal, v. XV, n. 1 e 2, p. 193-219, 2006.

PLACO, Vera Maria N. S.; SOUZA, Vera Lucia T. (Org.). Aprendizagem do Adulto Professor. São Paulo: Loyola, 2006.

SCHEAFFER, Richard L. Statistics for a New Century. In: BURKE, Maurice J.; CURCIO, Frances R. (Org.). Learning Mathematics for a New Century. Reston/ Virginia: NCTM, 2000. P. 158-173.

SHAUGHNESSY, J. Michael; GARFIELD, Joan B.; GREER, Brian. Data Handling. In: BISHOP, Alan et al. (Org.). International Handbook of Mathematics Education. Dordrecht: Kluwer Academic, 1996. P. 205-237.

SOUZA, Antonio Carlos. A Educação Estatística na Infância. 2007. 209 f. Dissertação (Mestrado em Ensino de Ciências e Matemática) - Programa de Pós-Graduação em Ensino de Ciências e Matemática, Universidade Cruzeiro do Sul, São Paulo, 2007.

SOUZA, Antonio Carlos. O Desenvolvimento Profissional de Educadoras da Infância: uma aproximação à Educação Estatística. 2013. 224 f. Tese (Doutorado em Ensino de Ciências e Matemática) - Programa de Pós-Graduação em Ensino de Ciências e Matemática, Universidade Cruzeiro do Sul, São Paulo, 2013.

Regina Célia Grando é licenciada em matemática pelo Imecc/Unicamp, mestre e doutora em Educação pela FE/Unicamp. É docente do Programa de Pós-Graduação Stricto Sensu em Educação da Universidade São Francisco. Tem experiência na docência na Educação Básica e no Ensino Superior. Suas pesquisas centram-se em formação docente e práticas pedagógicas. É coordenadora do Programa Observatório da Educação.

E-mail: regrando@yahoo.com.br

Adair Mendes Nacarato é licenciada em matemática pela PUC-Campinas, mestre e doutora em Educação pela FE/Unicamp. É docente do Programa de Pós-Graduação Stricto Sensu em Educação da Universidade São Francisco. Suas pesquisas centram-se em estudos biográficos, formação docente e práticas pedagógicas.

E-mail:adamn@terra.com.br

Celi Espasandin Lopes é licenciada em Matemática pela Unitau, graduada em Pedagogia, mestre e doutora em Educação pela FE/Unicamp. É professora titular do Programa de Pós-Graduação em Ensino de Ciências e Matemática da Universidade Cruzeiro do Sul. Desenvolve pesquisas sobre os processos de ensino e aprendizagem em Matemática e Estatística.

E-mail: celilopes@uol.com.br 